\title{
Investigation on the association between NLRP3 gene polymorphisms and susceptibility to primary gout
}

\author{
L.F. Wang ${ }^{1}$, Y.J. Ding ${ }^{1}$, Q. Zhao' ${ }^{1}$ and X.L. Zhang' \\ 'Department of Rheumatology, Huaihe Hospital of Henan University, \\ Kaifeng, China \\ 2Department of Nephropathy Rheumatology, \\ Third Affiliated Hospital of Xinxiang Medical University, Xinxiang, China \\ Corresponding author: X.L. Zhang \\ E-mail: zhangxiaoli_xl@163.com \\ Genet. Mol. Res. 14 (4): 16410-16414 (2015) \\ Received August 10, 2015 \\ Accepted October 25, 2015 \\ Published December 9, 2015 \\ DOI http://dx.doi.org/10.4238/2015.December.9.10
}

\begin{abstract}
We conducted a case-control study to investigate the association between 3 common NALP3 polymorphisms (rs10754558, rs7512998, and rs12137901) and the susceptibility to primary gout. A total of 320 patients with primary gout and 320 controls were included in this study. The genotyping of NALP3 rs10754558, rs7512998, and rs12137901 were conducted by polymerase chain reaction-restriction fragment length polymorphism. Comparison analysis showed that primary gout patients were more likely to have higher body mass index, prevalence of hypertension, blood glucose, triglycerides, urea nitrogen, and uric acid $(P<0.05)$. Logistic regression analysis revealed no significant association between the NALP3 rs10754558, rs7512998, and rs12137901 polymorphisms and the risk of gouty arthritis. In conclusion, we found no significant association between NALP3 gene polymorphisms and the risk of primary gout.
\end{abstract}

Key words: NLRP3; Polymorphism; Primary gout 


\section{INTRODUCTION}

Primary gout has become a common metabolic disease, which is manifested by higher urate concentration in the serum and acute arthritis in and around the joints (Terkeltaub, 1993; Bieber and Terkeltaub, 2004). In China, the incidence of primary gout has rapidly increased in recent years because of dietary and lifestyle changes. Previous studies reported that the prevalence of gout in eastern China is approximately $2 \%$ in men and $0.5 \%$ in women, while it was less than $0.1 \%$ overall 10 years ago (Miao et al., 2008). The development of gout is caused by multiple factors, including environmental and genetic factors (Qing et al., 2013; Cai et al., 2014; Li et al., 2014; Roddy and Choi, 2014).

Interleukin-1 $\beta$ (IL-1 $\beta$ ) is released by blood monocytes stimulated by monosodium urate monohydrate to mediate the inflammatory response. Moreover, caspase-1 catalyzes inactive prolL$1 \beta$ and influences the production of active IL-1 $\beta$. The expression of LRR and PYD domains-containing protein 3 (NALP3) is involved in the activation of caspase- 1 and the production of IL-1 $\beta$. Previous studies reported an association between NALP3 gene polymorphisms and the susceptibility to gout, but the results have been inconsistent (Miao et al., 2009; Meng et al., 2013). Therefore, we conducted a case-control study to investigate the association between 3 common NALP3 polymorphisms (rs10754558, rs7512998, and rs12137901) and the susceptibility to primary gout.

\section{MATERIAL AND METHODS}

\section{Patients}

A total of 320 patients with primary gout were recruited for this study from the Huaihe Hospital of Henan University. Primary gout was diagnosed according to preliminary criteria for the classification of gout of the American Rheumatism Association (Wallace et al., 1977). Gout was defined as uric acid levels $>420 \mathrm{mM}$ in males and post-menopausal women and as $>350 \mathrm{mM}$ in pre-menopausal women.

Additionally, 320 controls were collected from individuals who received health check-up examinations. All patients were confirmed to have no history of primary gout, hyperuricemia, or other inflammation-related diseases.

The demographic and clinical characteristics were collected from medical records. Informed consent was obtained from all participants they were enrolled in the study. The Ethical Committee of Huaihe Hospital of Henan University approved the study protocols, and all participants provided written informed consent according to the Declaration of Helsinki.

\section{DNA extraction and genotyping}

All patients and health controls were asked to provide $5 \mathrm{~mL}$ venous blood, which was stored at $-20^{\circ} \mathrm{C}$ until use and included $0.5 \mathrm{mg} / \mathrm{mL}$ EDTA as an anticoagulant. DNA was extracted from peripheral blood leukocytes using a commercially available Qiagen kit (Hilden, Germany). The genotyping of NALP3 rs10754558, rs7512998, and rs12137901 was conducted by polymerase chain reaction-restriction fragment length polymorphism. The primers for NALP3 rs10754558, rs358294199, and rs35829419 were designed using Sequenom Assay Design 3.1 software (San Diego, CA, USA). Amplification reactions were carried out with an initial denaturation step of 8 min at $94^{\circ} \mathrm{C}$, followed by 30 cycles at $94^{\circ} \mathrm{C}$ for $30 \mathrm{~s}$, annealing at $60^{\circ} \mathrm{C}$ for $30 \mathrm{~s}$, and extension at $72^{\circ} \mathrm{C}$ for $1 \mathrm{~min}$. 


\section{Statistical analysis}

The Statistical Analyses System package (version 8.01; SAS Institute, Cary, NC, USA) was used for statistical analysis. Differences between continuous variables were expressed by the mean $\pm S D$, while those between categorical variables were evaluated using frequencies and percentages. Deviations from Hardy-Weinberg equilibrium of NALP3 rs10754558, rs7512998, and rs12137901 were evaluated by $X^{2}$-test. Logistic regression was used to assess the influence of NALP3 rs10754558, rs7512998, and rs12137901 genetic polymorphisms on the susceptibility to primary gout. Associations were determined based on odds ratios and their $95 \%$ confidence intervals. These values were adjusted for potential confounding factors, and the wild-type genotype was used as the reference group. Differences for 2 -sided $P$ values $<0.05$ were considered statistically significant.

\section{RESULTS}

\section{Patient demographic and clinical characteristics}

The mean ages of the 320 primary gout patients and 320 controls were $52.6 \pm 10.5$ and $50.5 \pm 9.2$ years, respectively. Comparative analysis revealed that primary gout patients were more likely to have a higher body mass index, prevalence of hypertension, blood glucose, triglycerides, urea nitrogen, and uric acid $(P<0.05)$ (Table 1). However, there were no significant differences between the 2 groups in terms of sex, age, total cholesterol, and creatinine.

\section{Table 1. Demographic and clinical characteristics of the primary gout patients and controls.}

\begin{tabular}{|c|c|c|c|c|c|c|}
\hline Variables & Patients $(N=320)$ & $\%$ & Controls $(\mathrm{N}=320)$ & $\%$ & $t$ or $x^{2}$ value & $P$ value \\
\hline \multicolumn{7}{|l|}{ Age, years } \\
\hline$<55$ & 173 & 54.1 & 187 & 58.4 & & \\
\hline$\geq 55$ & 147 & 45.9 & 133 & 41.6 & 1.24 & 0.26 \\
\hline \multicolumn{7}{|l|}{ Gender } \\
\hline Male & 219 & 68.4 & 210 & 65.6 & & \\
\hline Female & 101 & 31.6 & 110 & 34.4 & 0.57 & 0.44 \\
\hline $\mathrm{BMI}, \mathrm{kg} / \mathrm{m}^{2}$ & & $24.5 \pm 2.6$ & & $22.7 \pm 3.5$ & 7.38 & $<0.05$ \\
\hline \multicolumn{7}{|l|}{ Hypertension } \\
\hline No & 170 & 53.1 & 232 & 72.5 & & \\
\hline Yes & 150 & 46.9 & 88 & 27.5 & 25.71 & $<0.05$ \\
\hline Blood glucose, mM & & $6.1 \pm 1.9$ & & $5.3 \pm 1.3$ & 6.22 & $<0.05$ \\
\hline $\mathrm{TG}, \mathrm{mM}$ & & $2.5 \pm 2.1$ & & $1.4 \pm 0.9$ & 8.61 & $<0.05$ \\
\hline $\mathrm{TC}, \mathrm{mM}$ & & $5.1 \pm 1.5$ & & $5.2 \pm 1.6$ & 0.82 & 0.21 \\
\hline Urea nitrogen, mM & & $6.05 \pm 2.3$ & & $5.7 \pm 1.5$ & 2.28 & $<0.05$ \\
\hline Creatinine, $\mathrm{mM}$ & & $90.6 \pm 31.5$ & & $93.2 \pm 20.6$ & 1.24 & 0.11 \\
\hline Uric acid, mM & & $484.2 \pm 126.6$ & & $317.4 \pm 62.4$ & 21.14 & $<0.05$ \\
\hline
\end{tabular}

The genotype frequencies of NALP3 rs10754558, rs7512998, and rs12137901 are shown in Table 2. Genotype distributions were found to be in line with Hardy-Weinberg equilibrium ( $P$ $>0.05$ ). We found no significant difference in the genotype distributions of NALP3 rs10754558, rs7512998, and rs12137901 between cases and controls (all P values > 0.05, Table 2). According to logistic regression analysis, no significant association was found between the NALP3 rs10754558, rs7512998, and rs12137901 polymorphisms and the risk of gouty arthritis. 


\begin{tabular}{|c|c|c|c|c|c|c|c|}
\hline Variables & Patients & $\%$ & Controls & $\%$ & HWE $(P \text { value })^{2}$ in controls & OR $(95 \% \mathrm{Cl})^{1}$ & $P$ value \\
\hline \multicolumn{8}{|c|}{ rs10754558 } \\
\hline $\mathrm{CC}$ & 136 & 42.5 & 146 & 45.6 & & - & - \\
\hline CG & 138 & 43.1 & 134 & 41.9 & & $1.11(0.78-1.56)$ & 0.56 \\
\hline GG & 46 & 14.4 & 40 & 12.5 & 0.29 & $1.23(0.74-2.06)$ & 0.39 \\
\hline \multicolumn{8}{|l|}{ rs7512998 } \\
\hline $\mathrm{TT}$ & 164 & 51.3 & 175 & 54.7 & & - & - \\
\hline TC & 129 & 40.3 & 124 & 38.8 & & $1.11(0.79-1.56)$ & 0.53 \\
\hline $\mathrm{CC}$ & 27 & 8.4 & 21 & 6.6 & 0.87 & $1.37(0.72-2.66)$ & 0.31 \\
\hline \multicolumn{8}{|c|}{ rs12137901 } \\
\hline $\mathrm{CC}$ & 146 & 45.6 & 159 & 49.7 & & - & - \\
\hline $\mathrm{CT}$ & 128 & 40.0 & 123 & 38.4 & & $1.13(0.80-1.61)$ & 0.46 \\
\hline $\mathrm{TT}$ & 46 & 14.4 & 38 & 11.9 & 0.07 & $1.32(0.79-2.21)$ & 0.26 \\
\hline
\end{tabular}

\section{DISCUSSION}

It is well-known that multiple mutations in the NALP3 gene are associated with hereditary inflammatory periodic fever syndromes in humans, such as Muckle-Wells syndrome, cold induced autoinflammatory syndrome 1 , and neonatal-onset multisystem inflammatory disease (Stojanov and Kastner, 2005; Masters et al., 2006; Pétrilli and Martinon, 2007; Church et al., 2008). There are more than 30 single-nucleotide polymorphisms (SNPs) in exon 3 of the NLRP3 gene, and these SNPs encode the nucleotide binding site domain and boundary regions (Aróstegui et al., 2004). Previous studies have reported an association between NALP3 gene polymorphisms and the susceptibility to gout (Miao et al., 2009; Meng et al., 2013), but the results of these studies are inconsistent. In our study, we found no significant difference between NALP3 polymorphisms and primary gout, suggesting that mutations in the NALP3 inflammasome may not be involved in the susceptibility to gouty development.

Several previous studies have reported the role of NALP3 gene polymorphisms in the development of gout in different ethnicities (Miao et al., 2009; Meng et al., 2013). Meng et al. (2013) conducted a study in a Chinese population including 480 cases with primary gouty and 480 control subjects to investigate the association between 17 SNPs in NALP3 and the susceptibility of gouty development. However, they found no significant association between NLRP3 gene polymorphisms and the risk of primary gouty arthritis. Miao et al. (2009) reported that functional mutations in NALP3 inflammasome may be genetic markers for gout. In our study, we investigated the role of 3 SNPs of NLRP3 in the etiology of gout, but found no significant association between NALP3 gene polymorphisms and the susceptibility to primary gouty. The discrepancies in these results may have been caused by differences in case and control selection, study design, and sample size.

Several limitations should be considered in our study. First, all patients and controls were selected from a single hospital, and thus selection bias may have influenced the results of our study. Second, additional SNPs may be involved in the susceptibility to primary gout and interact with the NALP3 gene polymorphisms. However, we only investigated the association between NALP3 gene polymorphisms and primary gout risk. Third, the sample size was relatively small in our study, which may have limited the statistical power in finding differences between groups. Therefore, further multicenter studies including larger sample sizes are greatly needed to confirm our findings. 
In conclusion, we found no significant association between NALP3 gene polymorphisms and the risk of primary gout. Further genetic studies including larger sample sizes are greatly needed to investigate the association between NALP3 gene polymorphisms and the development of primary gout.

\section{Conflicts of interest}

The authors declare no conflict of interest.

\section{REFERENCES}

Aróstegui JI, Aldea A, Modesto C, Rua MJ, et al. (2004). Clinical and genetic heterogeneity among Spanish patients with recurrent autoinflammatory syndromes associated with the CIAS1/PYPAF1/NALP3 gene. Arthritis Rheum. 50: 40454050.

Bieber JD and Terkeltaub RA (2004). Gout: on the brink of novel therapeutic options for an ancient disease. Arthritis Rheum. 50: 2400-2414.

Cai Y, Peng YH, Tang Z, Guo XL, et al. (2014). Association of Toll-like receptor 2 polymorphisms with gout. Biomed. Rep. 2: 292-296.

Church LD, Cook GP and McDermott MF (2008). Primer: inflammasomes and interleukin 1beta in inflammatory disorders. Nat. Clin. Pract. Rheumatol. 4: 34-42.

Li C, Yu Q, Han L, Wang C, et al. (2014). The hURAT1 rs559946 polymorphism and the incidence of gout in Han Chinese men. Scand. J. Rheumatol. 43: 35-42.

Masters SL, Lobito AA, Chae J and Kastner DL (2006). Recent advances in the molecular pathogenesis of hereditary recurrent fevers. Curr. Opin. Allergy Clin. Immunol. 6: 428-433.

Meng DM, Zhou YJ, Wang L, Ren W, et al. (2013). Polymorphisms in the NLRP3 gene and risk of primary gouty arthritis. Mol. Med. Rep. 7: 1761-1766.

Miao Z, Li C, Chen Y, Zhao S, et al. (2008). Dietary and lifestyle changes associated with high prevalence of hyperuricemia and gout in the Shandong coastal cities of Eastern China. J. Rheumatol. 35: 1859-1864.

Miao ZM, Zhao SH, Yan SL, Li CG, et al. (2009). NALP3 inflammasome functional polymorphisms and gout susceptibility. Cell Cycle 8: 27-30.

Pétrilli V and Martinon F (2007). The inflammasome, autoinflammatory diseases, and gout. Joint Bone Spine 74: 571-576.

Qing YF, Zhou JG, Zhang QB, Wang DS, et al. (2013). Association of TLR4 Gene rs2149356 polymorphism with primary gouty arthritis in a case-control study. PLoS One 8: e64845.

Roddy E and Choi HK (2014). Epidemiology of gout. Rheum. Dis. Clin. North Am. 40: 155-175.

Stojanov S and Kastner DL (2005). Familial autoinflammatory diseases: genetics, pathogenesis and treatment. Curr. Opin. Rheumatol. 17: 586-599.

Terkeltaub RA (1993). Gout and mechanisms of crystal-induced inflammation. Curr. Opin. Rheumatol. 5: 510-516.

Wallace SL, Robinson H, Masi AT, Decker JL, et al. (1977). Preliminary criteria for the classification of the acute arthritis of primary gout. Arthritis Rheum. 20: 895-900. 